\title{
ProteCtive COATINGS FOR CERAMIC SUPERPLASTIC FORMING DIES: AN INITIAL STUDY ON PROTECTIVE COATING PERFORMANCE
}

\author{
Andrea STAIANO ${ }^{1}$, Lynne O’HARE ${ }^{2}$, William ION ${ }^{1,2}$, Nicola ZUELLI $^{2}$ \\ ${ }^{1}$ Design, Manufacture \& Engineering Management, University of Strathclyde, Glasgow, UK \\ a.staiano@outlook.com \\ ${ }^{2}$ Advanced Forming Research Centre, Design, Manufacture \& Engineering Management, University of Strathclyde, \\ Inchinnan, UK \\ n.zuelli@strath.ac.uk
}

\begin{abstract}
Superplastic forming (SPF) is an advanced manufacturing process, typically restricted to low volume and high value products, where metallic sheets are heated at the superplastic temperature and blow formed into a metallic die. Refractory ceramics are a low cost option to substitute the high temperature resistant steels and other alloys conventionally used in SPF dies, but their brittle nature is a limiting factor for most SPF applications. Suitable surface coatings have shown a significant effect on wear resistance and can be employed to improve the ceramic performance in terms of tool life. This paper is focused on an initial study on protective coatings for SPF ceramic dies to evaluate their effectiveness for SPF forming. The tests were conducted using a dedicated test rig built at the Advanced Forming Research Centre (AFRC) at the University of Strathclyde, and where the die-blank interaction under SPF conditions was replicated at laboratory scale.
\end{abstract}

Keywords :

Superplastic forming; wear; ceramic die; protective coating; Ti-6Al-4V.

\section{INTRODUCTION}

Superplasticity is a deformation mode associated with the exceptional ductility that certain materials exhibit when deformed under specific strain rate and temperature. This phenomenon is used in the manufacturing process known as superplastic forming (SPF), where, as shown in Figure 1, a metal sheet is blown into a die at high temperature. Titanium alloys are commonly used in SPF for a wide number of applications in the aerospace, chemical, automotive and marine sectors [1], [2]. SPF is an attractive manufacturing process, particularly for titanium alloys, due to its achievable benefits which include [3]:

- Complex shapes can be formed;

- Weight and material saving can be realized;

- Little or no residual stress occurs in the formed part.

SPF dies are commonly made of heat resistant nickel-chromium cast steels, but such materials are expensive and have very long manufacturing lead-time. The total time to design, cast, machine and polish a metal die is typically three to eight months [1], [4]; that is a critical limiting factor for the improvement of the SPF process in mass production. Moreover, Lütjering and Williams [5] evaluated the cost of the SPF manufacturing process and identified the principal cost elements as the titanium sheet and the tools, which must withstand prolonged time at elevated temperatures. Recently, high temperature steels are being challenged by emerging materials such as ceramic refractories, which present a lower production cost and exhibit shorter lead-time [6], [7]. 


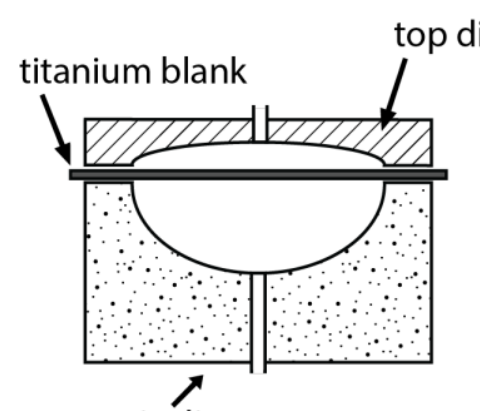

ceramic die
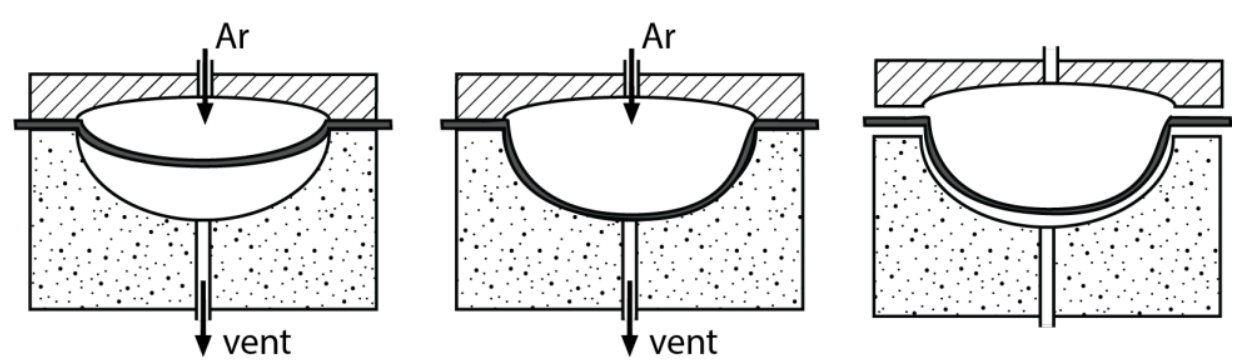

Figure 1: Schematic representation of a SPF process. The blank is loaded and heated to its superplastic temperature. The inlet valve on the top die allows the introduction of an inert gas (such as argon) forming the part. Once the part is formed, the top die is opened and the part removed.

Those emerging materials [7] can benefit the SPF process in terms of rapid prototyping and lower die cost. Refractory materials for SPF dies are interesting for their cost and their mechanical properties at high temperature, but their brittle behaviour determines their dominant failure mechanism, which is a limiting factor for the implementation in mass production. Solutions have been proposed to improve the overall ductility of ceramic dies using an ad hoc reinforced structure into the die [6], [8]. However, surface degradation can lead to micro cracks generation at the working surface, which will develop within the body over repeated cycles. Moreover, the quality of superplastically-formed parts depends on the conditions of the die surface and the lubricant on the work piece [9]. The most common quality defects on the die surface consist of scratches, machining marks, lubricant build-up and excessive roughness, which are reproduced on the part during the forming process. Typically, releasing agents are used to prevent sticking of the part on the die avoiding damages on the finished part surfaces. An ideal coating should be able to prevent the formation of cracks at the ceramic surface and, at the same time, it should act as releasing agent for the metal sheet part used in the SPF process.

In a previous work [10] an experimental procedure was developed to assess the surface condition of ceramic materials under SPF conditions. In this work, an initial study on potential protective coatings is carried out. Due to the lack of data in the literature regarding coating materials properties under SPF conditions (temperature resistance, toughness, brittleness, etc.), the experiments conducted in this work aim to assess the coating performance in order to generate a database of suitable coatings for a range of different process variables. The key metrics to evaluate coating performance are:

- resistance to thermal cycles,

- die surface degradation, and

- titanium scale accumulation.

\section{EXPERIMENTAL SETUP}

\subsection{DIE PART INTERFACE (DPI) RIG}

A test rig (Figure 2) was previously designed to evaluate the interaction at the die/part interface (DPI) under SPF process conditions. The test rig is capable of simulating the SPF process at laboratory scale, allowing for a range of different research projects to pursue process understanding and improvement. The rig is composed of two stacks. The bottom stack applies a load simulating the gas pressure in the SPF chamber. 

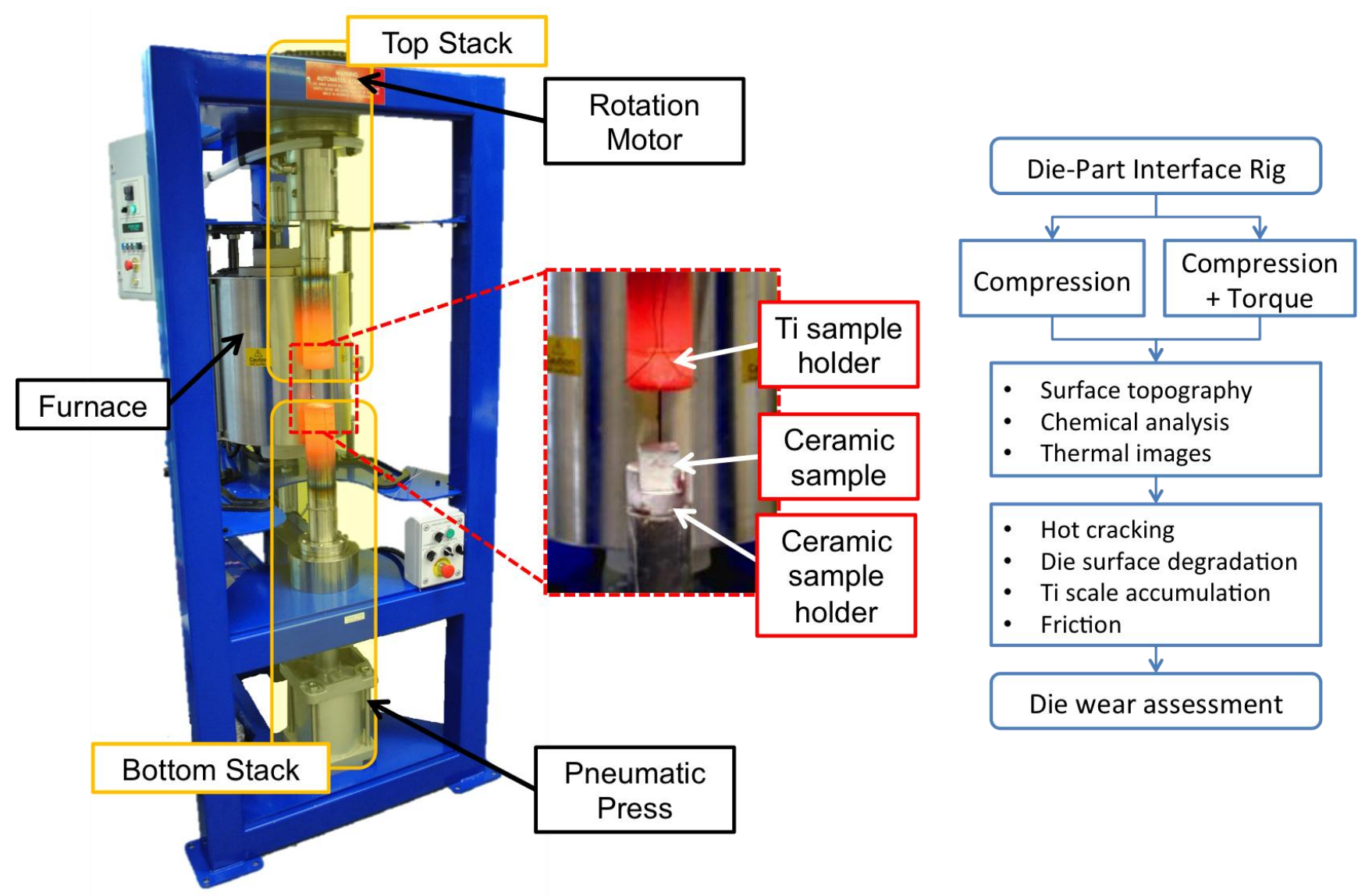

Figure 2: The test rig used to simulate the superplastic forming process. It features two stacks and a cylindrical furnace. Each extremity of the stack has an interchangeable tool, which can be either the sheet sample holder or the metallic/ceramic die holder.

The top stack is attached to a rotation motor, which applies a torque to the sample, simulating the sliding of the blank on the die surface during a real SPF process. Each extremity of the stack has an interchangeable tool that can be either the sample holder or a metallic/ceramic tool, depending on the die and sheet material to be tested. The rig is equipped with a cylindrical furnace, which wraps around both the stacks when in operation. The furnace is able to achieve operating temperatures up to $1000{ }^{\circ} \mathrm{C}$. The rig is connected to a control unit, which records temperature, applied normal force variation, rotation speed and torque. The rig is able to perform twist compression tests between the die/part surfaces. Furthermore, the rig is equipped with a thermal camera which records thermal images of tools during loading/unloading of the titanium sample to assess tool surface degradation over a number of SPF cycles.

\subsection{MATERIALS}

In the work described in this paper the ceramic substrate used for the experiment is a commercial casted refractory ceramic powder (Ceradyne ThermoSil® 220) already used for SPF dies. This powder is composed of fused silica reinforced with silicon carbide particles. The ceramic is cast in cubes of $50 \mathrm{~mm}$ per side following supplier instructions. Care is taken to attain parallelisms on the top and bottom surfaces in order to achieve a better load distribution during the experiment; parallelism is within $\pm 0.2 \mathrm{~mm}$ of tolerance. The top surface average roughness (Sa) of the uncoated ceramic is also controlled to achieve an Sa value below $10 \mu \mathrm{m}$. 

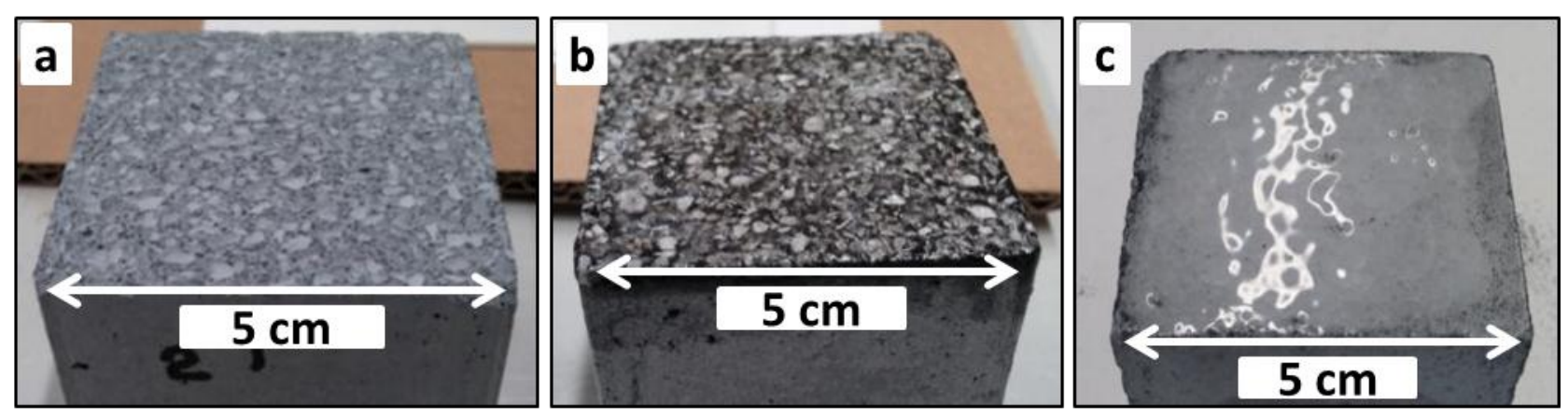

Figure 3: Uncoated ceramic die (a), Coating-1 (b) and Coating-2 (c) before testing.

The cast samples have density of $2100 \mathrm{~kg} / \mathrm{m}^{3}$ and coefficient of linear thermal expansion of $1.7 \times 10^{-6} /{ }^{\circ} \mathrm{C}[11]$. The coating materials are selected to fit the ceramic substrate and to be able to stand typical SPF operating temperature. The deposited coatings, which are showed in Figure 3, are composed of a mix of aluminosilicate powders with a specified composition, or were ceramic glasses available commercially. The metal sheet samples were made of commercial SPF grade Ti6Al-4V alloy with dimensions $40 \times 60 \times 1.2 \mathrm{~mm}$.

\subsection{MEASUREMENT SYSTEM}

The aim of the experiment reported here is to evaluate the resistance of coated and uncoated ceramic samples to thermal cycles, die surface degradation and titanium scale accumulation, as reported in a the authors' previous work [10]. Imaging confocal microscopy is employed for visual and quantitative measurement of 3D surface topography changes before and after the experiment. An Alicona Infinite Focus confocal microscope is used for the acquisition of a sequence of confocal images through the depth of focus of the surface; $5 \mathrm{x}$ magnification objective is used for the measurement, with $400 \mathrm{~nm}$ and $55.99 \mu \mathrm{m}$ as vertical and lateral resolution respectively. A Land Instruments FTI-E 1000 thermal imaging camera is installed to monitor the die condition insitu, and thermal images are recorded during the loading and unloading of titanium sheet specimens to monitor the ceramic surface degradation. A Quanta FEI scanning electron microscope (SEM) is used for visual and chemical inspection of sample cross sections and fractography for failure analysis.

\subsection{EXPERIMENTAL CONDITIONS}

The test rig features two operating modes: compression and compression with torque. In this paper the results from the compression mode test are discussed. The range of applied loads, temperatures and cycle times used for the experiments is based on real process condition in SPF. The major advantage of the DPI rig is the ability to control to a high level of accuracy the input parameters. The applied temperature for the test is set above $850{ }^{\circ} \mathrm{C}$, in order to be in the superplasticity region of the Ti-6Al-4V samples. The normal load applied varies from 1 to $3 \mathrm{MPa}$. The load distribution in the rig is inspected before the experiment using pressure distribution films (Prescale LW, Fujifilm). The test featured a sequence of SPF cycles in order to investigate the ceramic surface wear part after part. The number of cycles is set to a minimum of 10 , and the experiment is interrupted if the coating or the ceramic fails (by break or melt) during the test. For the test, a boron nitride (BN) suspension (Kennametal WJMB grade) is sprayed on each side of each Ti-6Al$4 \mathrm{~V}$ sample as a release agent. A precision scale (resolution $0.001 \mathrm{~g}$ ) is used to apply a constant amount of release agent to each face of the Ti-6Al-4V samples. 


\section{$11^{\text {th }}$ EUROSPF Conference}

\section{RESULTS}

\subsection{RESISTANCE TO THERMAL CYCLES}

Confocal microscope images were obtained for the ceramic sample before and after the DPI test to compare the surface morphology. Figures 4-a and 4-b show the uncoated ceramic surface before and after test respectively. The roughness $\mathrm{Sa}_{(\mathrm{i})}$ of the uncoated ceramic was $25 \mu \mathrm{m}$ initially and 28 $\mu \mathrm{m}$ after 15 cycles. The value of roughness Sa did not change significantly, whereas the volume of valleys accumulation (Vvv) decreased from $12 \mathrm{~cm}^{3} / \mathrm{mm}^{2}$ to $8 \mathrm{~cm}^{3} / \mathrm{mm}^{2}$, indicating that the surface porosity was filled in with material (BN and oxides) during the experiment. The uncoated ceramic surface topography before and after the test shows no evident wear, except some BN built-up in some regions of the surface. Thermal images (Figure 5-a and 5-b) acquired before and after test did not reveal any significant damage or crack on the uncoated ceramic surface.

Figures 4-c and 4-d show Coating-1 before and after the test. The initial roughness $\mathrm{Sa}_{(\mathrm{i})}$ is $60 \mu \mathrm{m}$ and the final roughness after 10 cycles is $38 \mu \mathrm{m}$. The roughness parameters of material volume of valleys and peaks of the ceramic surface before and after the test indicate that the surface wear was due to material accumulation inside voids and material removal from asperities. Thermal images (Figure 5-c and 5-d) of the surface before the test and after unloading of the Ti-6Al-4V parts show localised accumulation of $\mathrm{BN}$ and oxides on the surface.
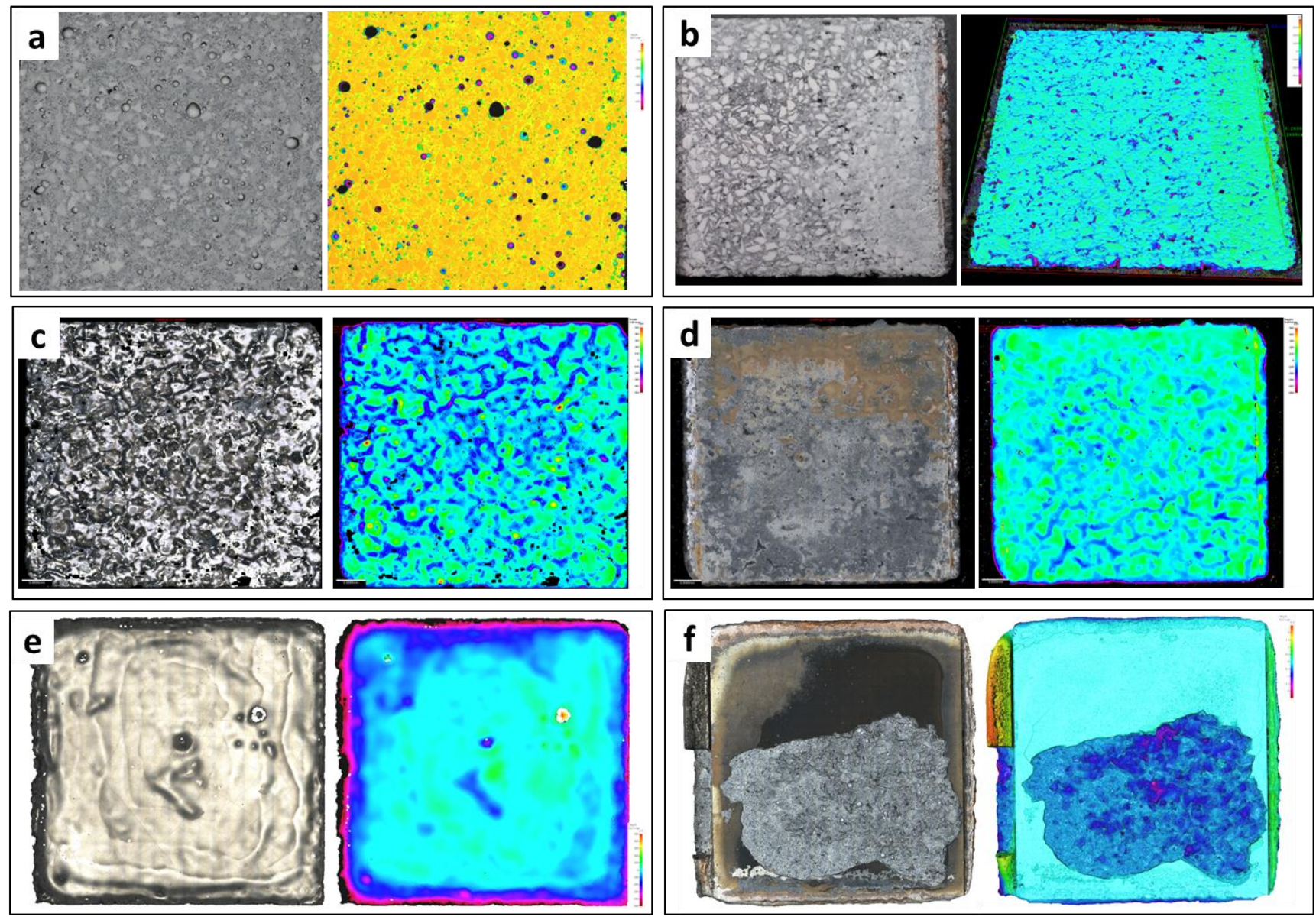

Figure 4: Surface picture (left) and 3D topography (right) obtained with confocal microscope imaging technique of uncoated ceramic before $(a)$ and after (b) test; ceramic with coating 1 before (c) and after $(d)$ test; ceramic with coating 2 before $(e)$ and after $(f)$ test. 

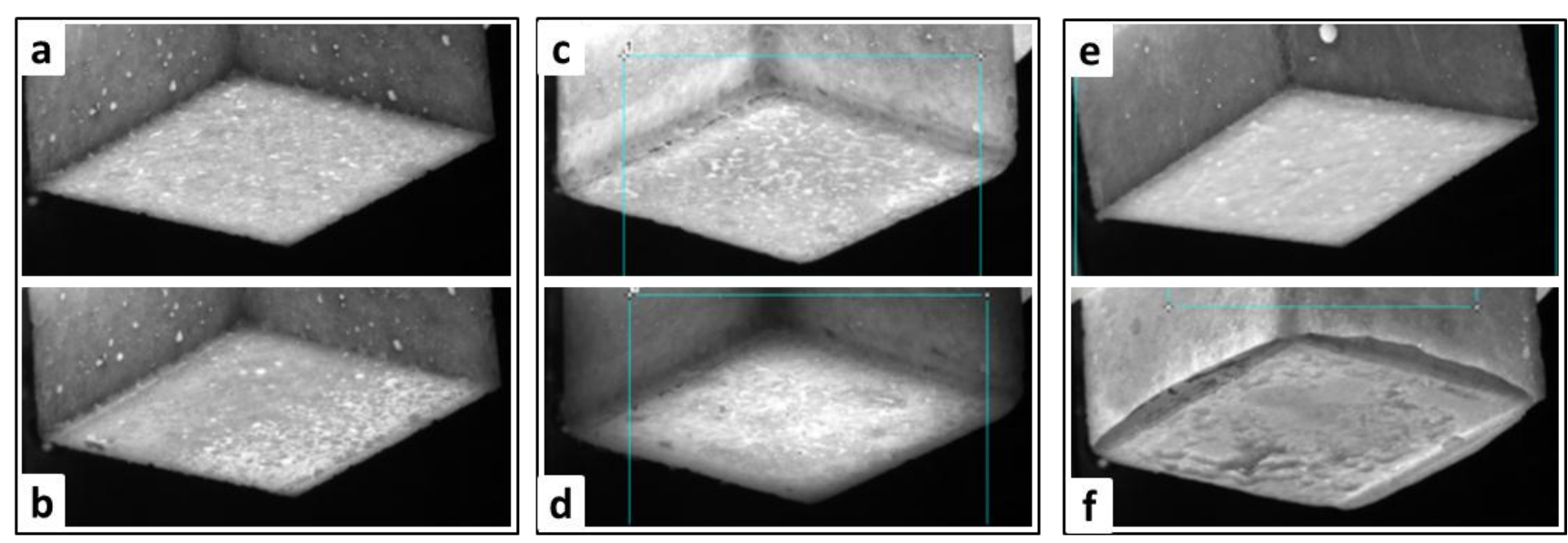

Figure 5: Thermal images recorded before and after the experiment for the uncoated ceramic $(a, b)$, Coating-1 (c,d) and Coating-2 (e,f).

Coating-2 surfaces before and after the test are showed in Figures 4-e and 4-f. The coating failed during the test, coming off from the surface while unloading the Ti-6Al-4V sample and damaging the ceramic substrate. The initial roughness of the coating is $15 \mu \mathrm{m}$ and its final roughness (in the undamaged area) is $10 \mu \mathrm{m}$. Coating- 2 shows softening during the test, being spread to the border of the ceramic sample when titanium part is pressed onto it (see thermal image in Figure 5-f). Moreover, the coating failed at the $6^{\text {th }}$ cycle due to the adhesion of the titanium part to the softened coating.

\subsection{DIE SURFACE DEGRADATION}

Due to the high temperatures used for SPF, the degradation of the ceramic die surface could not be analysed after each cycle, thus the change in roughness of each Ti-6Al-4V sample was analysed as a parameter of the die wear instead. It was expected that the titanium samples would have mirrored the die surface wear during the SPF process. The roughness parameters of the sample have been studied as a function of the cycle number, and normalised with the starting roughness of the ceramic substrate used during the test (Figure 6-a). The Ti-6Al-4V samples formed onto the uncoated ceramic show a trend where the surface roughness of the titanium sample $(\mathrm{Sa}(\mathrm{Ti}))$ increased at each cycle (black squares in Figure 6-a), indicating wear of the ceramic die surface. The surface roughness of the Ti-6Al-4V samples formed on Coating-1 (red circles in Figure 6-a) remained constant over the ten samples tested, and the value of the surface roughness of the titanium sample $\mathrm{Sa}(\mathrm{Ti})$ is always lower than the roughness of Coating-1 before the test $\mathrm{Sa}_{0}(\mathrm{Die})-$ $\mathrm{Sa}(\mathrm{Ti})<1$. This result suggests that the wear mechanism is characterised by removal of coating material since the very first titanium sample. The formed samples on Coating-2 (blue triangle in Figure 6-a) show very low value of roughness until the coating broke as indicated, denoted by the sudden increase of the value $\mathrm{Sa}(\mathrm{Ti}) / \mathrm{Sa}_{0}(\mathrm{Die})$ ratio.

The ease of removal of each metallic sample is recorded in a qualitative scale from 1 to 5 , where 1 indicates that the Ti-6Al-4V did not stick to the die surface, thus it was really easy to remove, and 5 indicates that the adhesion was so strong that the removal damaged the die surface. According to the SPF users experience in forming of Ti-6Al-4V, the authors considered a value equal to 3 to be similar to the resistance experienced removing an SPF part from a die in an industrial press. 


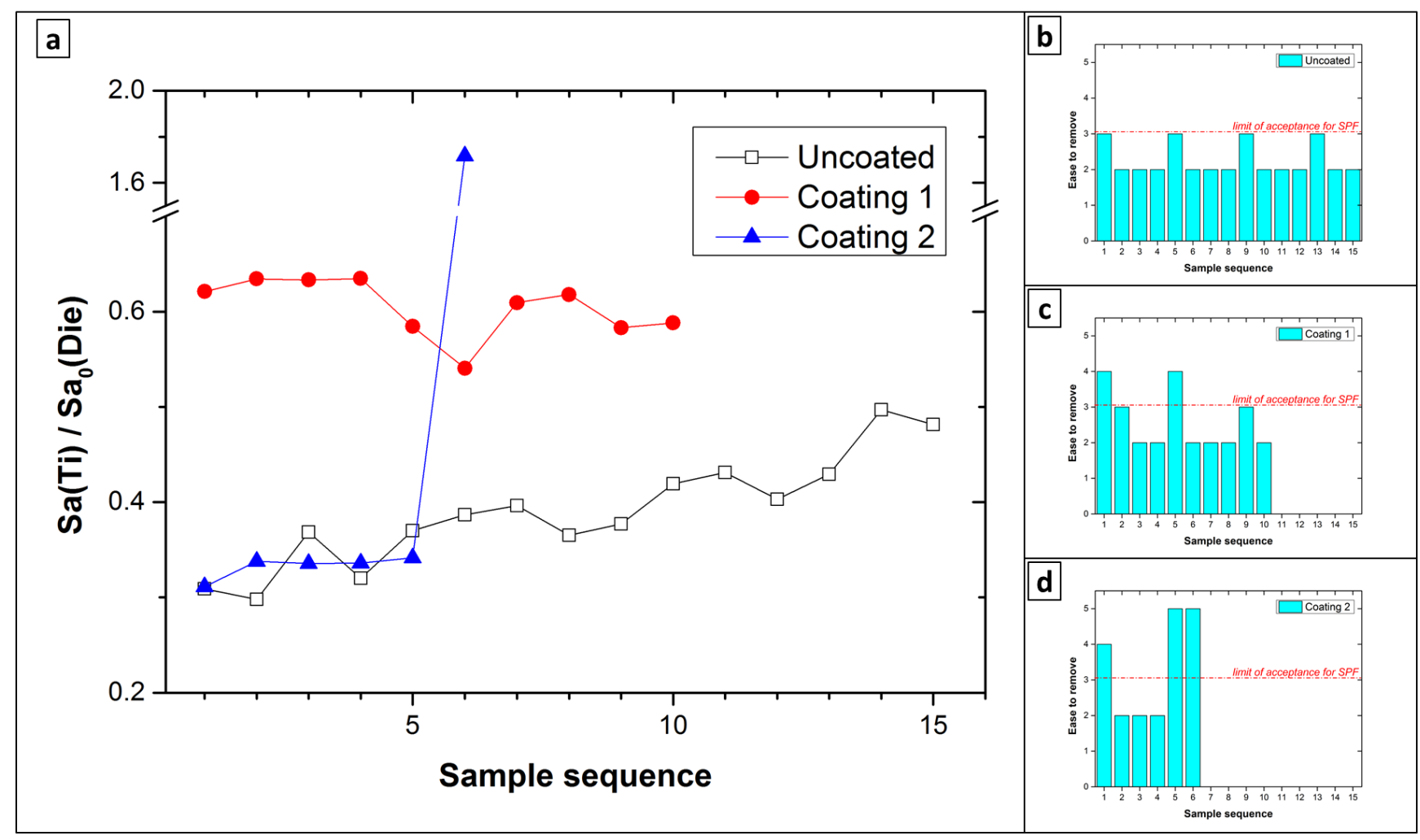

Figure 6: (a) Surface roughness of each Ti-6Al-4V sample Sa(Ti) normalised with the roughness of the ceramic substrate (or coating) before the test $\mathrm{Sa}(\mathrm{Die})$. The ease of removal of the Ti-6Al-4V samples from the die after test was evaluated qualitatively in a scale from 1 (very easy to remove) to 5 (surface damaged when removed) and are shown in (b) for the uncoated ceramic, (c) for Coating-1 and (d) for Coating-2.

For the uncoated ceramic (Figure 6-b) the ease of removal value did not exceed the limit of acceptance, however it is worth highlighting that the first part of the day is always the most difficult to remove. On the other hand, the coated ceramic (Figure 6-c and 6-d), caused difficulty in removing the metallic sample due to the adhesion of titanium parts to the coating under SPF conditions, even resulting in fracture of the surface as observed in Coating-2.

\subsection{TITANIUM AND OXIDES SCALE BUILT-UP}

Oxide scale built up on the die surface during the SPF cycles. The SEM images in Figure 7-a show a multilayer composed of titanium oxide, vanadium oxide, boron oxide and boron nitride built-up on the uncoated ceramic die. The multilayer has thickness of about $50 \mu \mathrm{m}$ and it was generated by the chemical interaction at SPF temperature between air, Ti-6Al-4V and BN. The multilayer adhered to the ceramic surface, which might have caused damage to the ceramic surface during unloading of titanium sample at the end of the SPF cycle. Energy dispersive X-ray (EDX) spectra have been obtained to study the element composition of a number of inspected regions. EDX spectra provided information about the oxide multilayer, which was composed mainly of titanium, vanadium, oxygen, silicon, aluminium, nitrogen and boron. The boron element was identified via wavelength dispersion spectroscopy (WDS) as EDX resolution for light elements is limited.

The cross section of Coating-1 after the test (Figure 7-b) shows a 30-40 $\mu \mathrm{m}$ oxide layer built-up on top of the coating (a close-up of the oxide multilayer is shown in Figure 7-c); a core layer of Coating-1 with a thickness of about $50 \mu \mathrm{m}$, and a 50-200 $\mu \mathrm{m}$ thick intermix layer in between. The intermix layer is composed by ceramic substrate matrix and melted coating. 

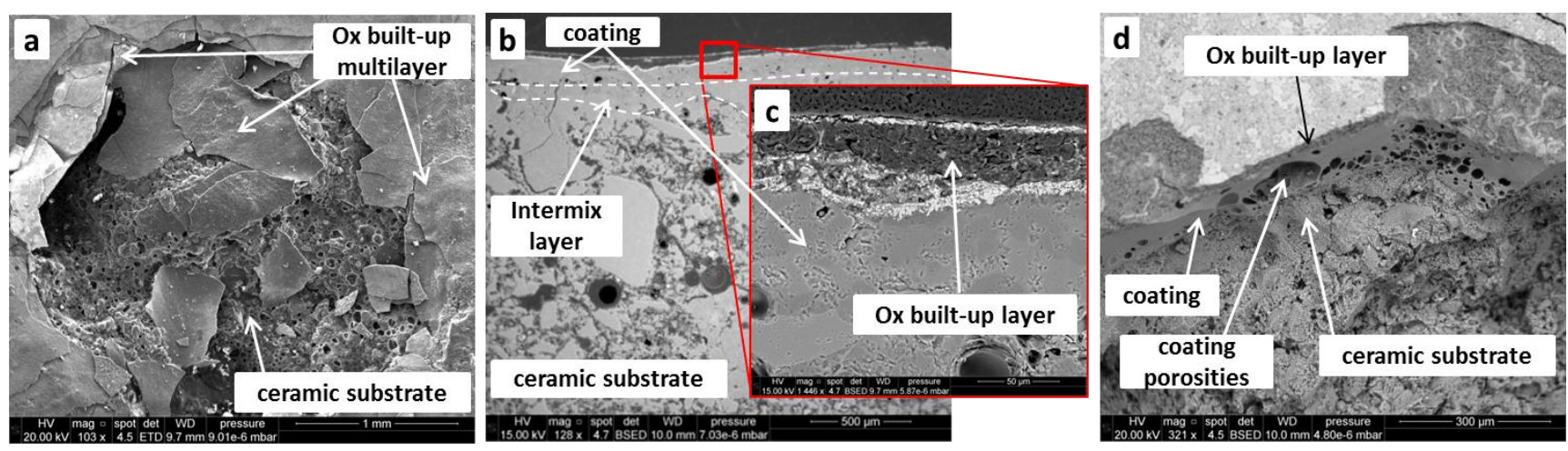

Figure 7: SEM images of (a) top view of the uncoated ceramic after the test; (b) Coating-1 cross section after the test and (c) close-up of the cross section of the oxides layer built-up; $(d)$ top view of Coating-2 after the test.

There is not a well-defined 'border' between substrate and coating, and this indicates good adhesion properties of the coating to the substrate. The cross section of the sample in Figure 7-b shows that the ceramic is composed of a bimodal distribution of the diameter of fused silica grains: one of the order of $50 \mu \mathrm{m}$ and one of the order of $500 \mu \mathrm{m}$. These fused silica grains are surrounded by calcium alumina binder and silicon carbide particles.

Figure 7-d shows a top view of the fracture edge where the coating failed. The SEM image shows at the top the oxides layer built-up, then a 100-150 $\mu$ m Coating-2 layer (white uniform colour) and at the bottom the ceramic substrate. The Coating-2 surface fracture shows brittle behaviour, due to the fact that the coating was mainly composed of a glass phase. In addition, Coating- 2 shows high porosity at the interface with the substrate, hence worsening the physical properties of the coating. Furthermore, Coating- 2 does not show an intermix layer as Coating- 1 . The glass phase, the high porosity at the interface coating-ceramic substrate and the absence of intermix layer are the main causes of the failure of coating 2 .

\section{Conclusions}

In this paper an experimental procedure, previously developed to assess ceramic die condition during superplastic forming (SPF) of titanium alloys was applied to characterise the performance of two different coatings and to compare them to the performance of an uncoated ceramic die. The experimental procedure replicated the die-part interface condition during the SPF process and was followed by part surface topography analysis to assess the surface wear since the surface of superplastically tested Ti-6Al-4V parts strongly depends on the conditions of the die surface.

The uncoated ceramic die did not show critical signs of die degradation but the part tended to stick to the surface of the die, which can be a cause of wear during the die lifecycle. Coating- 1 shows good results in terms of thermal cycle resistance and die degradation, but the difficulty to remove titanium parts is a limiting factor for this coating to be transferred into manufacturing. Coating-2 fails after only six SPF cycles, thus it is not suitable for SPF applications.

The results indicate that the selected coatings have poor performance in terms of protection of the ceramic die, thus are not indicate for mass production. The presented test method is able to assess ceramic surface wear and coating degradation under SPF conditions in laboratory. This means that with this test is possible to investigate ceramic die surface improvements in a cheaper, easier and faster manner than the employing a SPF press. With this paper, the authors want to demonstrate the applicability of such a developed test; further work needs to be conducted on other identified coating materials. 
This paper demonstrated a method for evaluating coatings for tool ceramic materials for superplastic forming. This method can be used to assess the influence of different process parameters on the die wear at laboratory scale and systematically evaluate several coating solutions available on the market.

\section{ACKNOWLEDGEMENTS}

This work is supported by the department of Design, Manufacture and Engineering Management (DMEM) of the University of Strathclyde, the Advanced Forming Research Centre (AFRC) and the Engineering and Physical Sciences Research Council (EPSRC).

\section{REFERENCES}

[1] D. G. Sanders, "Superplastic forming manufacturing technology moves towards the twenty-first century," Mater. Sci. Forum, vol. 304-306, pp. 805-812, 1999.

[2] S. S. Jiang and K. F. Zhang, "Superplastic forming of Ti6Al4V alloy using ZrO 2 -TiO 2 ceramic die with adjustable linear thermal expansion coefficient," Trans. Nonferrous Met. Soc. China, vol. 19, no. June, pp. 418-422, 2009.

[3] C. Leyens and M. Peters, Titanium and Titanium Alloys. Weinheim, FRG: Wiley-VCH Verlag GmbH \& Co. KGaA, 2003.

[4] G. Bernhart, F. Nazaret, and T. Cutard, "Fiber reinforced refractory castables for SPF toolings," Materwiss. Werksttech., vol. 39, no. 4-5, pp. 317-321, 2008.

[5] G. Lütjering and J. C. Wiliams, Titanium. Berlin: Springer Berlin Heidelberg, 2007.

[6] D. G. Sanders, "A Production System Using Ceramic Die Technology for Superplastic Forming," Mater. Sci. Forum, vol. 447-448, pp. 153-158, 2004.

[7] G. Bernhart, F. Nazaret, and T. Cutard, "Fibre Reinforced Refractory Castables : an Alternative Solution for SPF Die Manufacturing," Mater. Sci. Forum, vol. 551-552, p. 37, 2007.

[8] A. Mazzoni, G. Bernhart, and T. Cutard, "Ceramic Fibre Reinforced Refractory Castables for Very High Temperature Superplastic Forming," Materwiss. Werksttech., vol. 43, no. 9, pp. 758762, Sep. 2012.

[9] A. T. Morales, "Evaluation of die coatings for superplastic forming processes," in Advances in superplasticity and superplastic forming : proceedings of a symposium held during the 2004 TMS Annual Meeting, 2004, pp. 51-64.

[10] A. Staiano, W. Ion, and L. O'Hare, "Monitoring of ceramic die condition under hot forming processes," in Proceeding of the 23rd CAPE conferece, 2015.

[11] Ceradyne-Thermo, "Ceradyne Thermo-Sil Product information." [Online]. Available: http://www.ceradyne-thermo.com/uploads/Ceradyne_Thermo_Materials_ThermoSil_Fused_Silica_Materials_12-15-03.pdf. [Accessed: 05-Oct-2013]. 